\title{
VIRTUAL REALITY AND ESTIMATING PRACTICE: A SOFTWARE SELECTION MODEL FOR ESTIMATING
}

\author{
Oluwole Allfred Olatunji \\ School of Architecture and Built Environment, Faculty of Engineering and Built Environment, \\ University of Newcastle, Callaghan, NSW, Australia \\ *Corresponding author (oluwole.olatunji@newcastle.edu.au)
}

\begin{abstract}
Construction estimates are a product of rigorous data analysis involving sophisticated data from a diverse range of multi-disciplinary sources. These data, often voluminous, are of different quality and are set to achieve slightly different goals which are not necessarily identical to the goal of the estimator. They are also engineered in different technologies which an estimator must be able to manipulate in other to achieve substantial success. Virtual Reality (VR) is an example of contemporaneous practice innovations where estimators are likely to require new set of tools to: (1) ingrain their integration in VR processes, (2) perform their roles conventionally and contemporaneously, and (3) sustain their commitment to the future of digital transactions in the construction industry. This paper advances a process model for defining ad selecting estimating applications that work well in VR project.
\end{abstract}

Keywords: Computer-aided Estimating, Estimating Practice, Integration, Iinteroperability ISO, Virtual Reality.

\section{INTRODUCTION}

Top on estimators' lists of priority assignments includes organizing a system that is robust enough to accommodate voluminous data from different sources, and be able to compare and process them at the appropriate speed, show every necessary detail and engineer accuracy to the highest possible level. There is no evidence in literature against the fact that information technology is the best way to go in achieving this.

Commercial software packages for estimating have been in existence since the 1970's [1]; trials, professional research and non-commercial uses of these systems may have started about a decade before this time. Other studies have also researched into how these earliest forms of CAE systems were used. Although some evidence by [2] have outlined how these earliest forms of CAE systems were used for virtually all forms of estimating practices in building and civil engineering works, however [3] argued that many CAE application at this time are limited to arithmetic functions only.

After first generation CAE systems, other applications have been developed to keep pace with advancements in design and business management disciplines. A research by [4] in 1995 listed CAE application used in Australia to include digitizers and dedicated estimating applications like Buildsoft, Ripac, Everest, FinCash, Microsoft Project, Estimator II, ROSS, In-House, Job Express, Fast Track, PC Estimator, West, Texy Est and others. According to these authors, other applications used by estimators include CAD of different forms e.g. AutoCAD, Turbocad, Autosketch, Cadvance, Macdraft, Datacad and Corel Draw. With these applications, estimators can perform virtually any form of professional responsibility that may be expected of them as much as these applications will allow them.

Beyond marketing persuasions, it is hard to identify why some estimators choose certain CAE application over 
others. Up to now, there are no customized universal standards for estimating discipline regarding functionality and performance qualities which estimating applications must conform to? As indicated in [4], some estimators are still reluctant to use any form of CAE application for their work. Although these authors concluded that such estimators have limited propensity for relevance in the event of VR, however can there be an acceptable justification for such reluctance? Potential justifications for this dis-incentive have been identified by [5-7]

\section{A BRIEF HISTORY OF IT IN ESTIMATING PRACTICE}

In 1957, Hanratty, known as the Father of $C A D D / C A M$, developed the first commercial numerical-control programming system called PRONTO. This was after an earlier version of graphic system that was designed at Massachusetts Institute of Technology (MIT) and used by the United States Army. As indicated by [8], there were other clues that CADD applications have been run on turnkey systems at MIT since 1931 - this is several decades before computers were so named. During this time, Integraph, Accugraph and MacDonal Douglas GDS were run on IBM, Prime, Digital VAX, Sun Systems and UNIX.

Few years after Hanratty's work, Prof. Charles Eastman developed a library of architectural elements which can be assembled and drawn on screen into a complete design concept. In 1962, a CAD-compliant form of digitizer was developed to enable automatic control of analogue inputs and subsequent transmission for a range uses in digital forms. Although for two decades after this, the proliferation of IT uses in design and construction industries, especially involving CAD and CAE applications, was not very popular due to high skill demand and cost. However, in the 70's, there is a small range of CAE applications; only large construction companies could afford them and they are deployed on very large projects.
Generally, during this time,, estimators have limited options to choose from, and it was unclear whether these applications actually improved how estimators do their works.

The first ever publication on computer-aided estimating was by [2]. The authors developed a standalone application that allows estimators to interact with a range of libraries and databases. The application was able to run on CROMECO and Prime computers. After this, IBM released Lotus 1-2-3 in 1983, a commercial form of spread-sheet application. As the cost hardware and software continued to reduce, and the success of Lotus 1-23, other CAE applications proliferated. In the 1980's and 90's, both commercial and standalone applications for estimating services increased in number markedly. Applications that were used for estimating and cost control purposes in building and civil engineering works at this time have been listed by [9].

Between 1990 and 2000, there is a wide variety of options for estimators to pick from; costs of hardware, software, knowledge acquisition and system maintenance are better than what it used to be, and there are more skilled persons to run the systems. It was also clearer at this point that CAE has a lot to offer estimating practice as outputs were faster, cheaper and are more desirable than manual methods. In the last decade, CAE applications have reshaped estimating practice even further; estimators can now engage in integrated services, communicate via remote and networked mediums, access sites remotely and use RFID and mobile technology for a wide range of purposes on a project [10]. Apart from CAE applications, neural networks and hybrid artificial intelligence have added another dimension to the impact of IT on estimating practice[11-13].

Surprisingly, a small portion of estimators surveyed by [4] were unwilling to use computers and CAE applications. 
Possible reasons given by $[14,15]$ include the fact that, at this time, outputs from computers often reflect processing errores, omissions and possible consequences of inefficnet programming. Therefore, many estimators would rather use manual methods and desktop applications to enhanced how they package their judgments instead of over-relying on computers which can jeoparidze the delicate processes that they intend to protect. The time spent in correcting errors in automatically generated estimates is yet another dis-incentive. Over time, these insinuations have changed. An appropriate use of IT is not only vitally essential for estimating practices to be relevant in a modern world; IT is now the most popular language of the business world. According to Sher et al. [16], non-compliance is tantamount to redundancy.

\section{CATEGORIZATION OF EXISTING SOFTWARE APPLICATIONS FOR ESTIMATING PRACTICE}

Construction estimates are generated in different stages; conceptual estimates during project concencpeutlization and initiation, comprehensive estimates during bidding and tender action, cost control and resource planning during construction, and lifecycle costing throughout project life. Different applications have been targeted at these stages in in patterns that suggest certain applications can perform better in some areas of estimating processes than others. For example, $[17,18]$ have categorized CAE programs as programs for BoQ drafting and BoQ pricing. Others listed by this author are those for arithmetic functions, those for solving specific estimating problems, project planning, predicting cashflow and for managing databases. The only addition made to these by [4] are communication programs. Similar studies on this subject by [19] and [20] failed to indicate any other new areas of estimating where information technology are being applied. Categories of business management and CAE applications are listed as follow: (See Table 1 in appendix for a summary):
Quantification applications: These programs are used for quantity measurement. There are three forms of these; Manual data input programs, automated quantity extraction programs, and Integrative quantity data extraction and exchange management programs. Manual data input programs allow users to input every primary variable such dimensions, descriptions, units and rates, while the system finalizes arithmetic computations and packaging. Examples include Spreadsheets, Timberline, WinQS, Ripac, Buildsoft and Everest.

Automated quantity extraction programs can view and calibrate drawings in .pdf, .dwg and .jpeg formats. They can also extract dimension automatically from drawings and flexibly apply description libraries to these quantities. Most of these programs are already 3D-compliant. Examples include Synchro, CostX, MasterBill, QSCAD, WinEx Master, Innovaya, Tocoman, Vico, and purpose mde application such as On-Screen take-off professional, Earthwork excavation software, Carlson estimating software

Integrative quantity data extraction and exchange management programs extract data from drawings and BoQs, and extend same for project planning and business management operations. An example of these includes Construction Computer Software. Moreover there are programmed Standards on data exchange. These include EDIFACT, EDIBUILD, EDICON and ASCII.

Data Extraction programs: These programs enable estimators to explore data from different source files such as quantities measurement files, estimating cost files, resourcing files, design, fabrication and construction specifications file, process planning files, business accounts and data files from communication networks. These sources may rely on customized programs for 
targeted functions. Depending on the nature of the project and forms of data involved, there is a wide range of ITenhanced data extraction workbenches there are used as database managemet programs. Generally, most of them are developed for entering and retrieving data from computer-managed databases. Examples include BuildTool, Job Simplicity, Profitool 6, BuilderTrend, e-business solutions, EADOC, EPCM Omnicom, PlansandSpecs and PENTA Construction ERP

Moreover, there are ther forms of extractors from customized to general-purpose platforms. Examples include Page Extractors, Web Scraper Plus+, IntelliGet and Mozenda Basic. Other software packages in this category are those that convert audio to text files. They include voice recognition programs and other programs that convert .mp3 and .mp4 files to text files. Commercial programs in this category include Dragon Natural Speaking 8, MacSpeech iListen and QPointer Voice. Apart from these, there are programs for data capture from remote locations. They enable estimators to capture and track labour, equipment, material and subcontractor information as it happens on site. Examples include Digital Time Capture software and RFID programs.

Pricing applications: These include programs for managing e-tendering processes, online sourcing applications, price database/arithmetic operations, and those for probabilistic and linear programming operation. E-tendering applications include Tenderer, iSpec, TenderSystem and eRFX management solution. MATLAB extracts price from online sources, while applications for arithmetic operations include spreadsheets, Estimator VJ and Estimator V6, PC Estimator, SEER, Ezy Estimator, Construction Computer Estimating (CCS) and ProEst. In addition to these, Probabilistic and Linear Programming packages allow business managers and consultants to solve problems on stock cutting, scheduling, resource allocation, operations research, among others.

Resourcing and Planning programs: There are three categories of construction project planing; resource schedulers, planning applications and cashflow programs. Examples of scehdulers include BuildIT, Virtual Boss and Schedule 1. Programs such as MS Project, Primavera, Astadevdev Powerproject, Timeline, Macproject, Microplanner and Ivan are examples of popular project planning applications. Software packages for cashflow analysis and management include FinCash, Maestro Solutions and Construction Computer Estimating (CCS).

Business management applications: these applications that are used for sundary purposes in estimating organizations. Such purposes include Data securitization, Digital communication, Progress and Asset tracking applications, Order management, Accounts' management programs and Database management applications. While CORTEXE, Deloitte and PoolDesigner are used for data securitization, G-SNART, and IntelliTrack are used for Progress and Aset tracking. Programs such as Explorer, Accubuild and Spectrum are used for Accounts' management.

A previous study by [4] have also identified the use of single and multiple user computer systems in estimating organizations. These authors also showed that single user machines appear as standalone and networked systems, and are driven by the likes of Linux, Windows and Mac. On the other hand, multiple user systems used by estimators have also been driven by windows and DOS, Pick, Unix, Mix, Frigitise, AMOSL, Novell and other. Apart from commercially available applications, there are indications that many construction estimators have used several forms of customized and standalone applications for any form of uses they may choose to. 


\section{SOFTWARE SELECTION VARIABLES}

Unlike in the design industry where CAD is very popular, there is a range of options for estimators to pick from either for general-purpose or project-specific functions. However, most of these applications work in different ways and hardly interoperate, even those in the same category. They also have different functional lives, compatibilities and are driven in slightly different ways in different machines. Therefore, to achieve appropriate business objectives, estimating practices have to make a lot of risky decisions in choosing what applications will be appropriate for their business in the short, medium and long term scenarios. Apart from these, they also have to decide on choosing appropriate combination of applications for specific tasks as well as decision on their maintenance, technical support and allied supplementation.

Regrettably, most estimators are not first-hand IT expert. At best, they rely on marketing impulses and persuasions to make decisions on what software package to go for, when and how. This, according to [21], portends a lot of risks for any business. Paradoxically, there is inadequate knowledge in available resources on how decisions are made on software selection in construction businesses. One of the very few works on this subjects [22], only concentrates on using an expert system, ESSEX, to determine the appropriateness of selecting software applications for quantity take-off and cost estimating. The single most important challenge of this model is the fact that these targeted activities are few compared to other numerous but vitally important roles which an estimator may perform with other applications. And, because the outcome and procedure of use a particular application is different, the model by [22] on software selection may not be the best way to go.

One of the models used in other fields e.g. [23], have relied on the guidelines of the International Organization for
Standardization and International Electrotechnical Commission on software quality standard [24]. Over a decade on, this ISO/IEC Standard, Standard 9126-1, needs to be domesticated in the context of estimating practice in construction business. This is simply because of the peculiarity of estimating practice and the dynamic factors that determine software selection in the construction industry.

\section{CONCLUSION}

Rather than being an advantage, proliferation of software applications for estimating practices is indeed a major risk. This has been made very clear by [14] as some of these applications may not reflect what vendors promised them to be, especially in the long run. This situation may be aggravated when there are major changes in certain aspects of software packages in other disciplines. When these changes cannot be fixed by regular updates such application may become redundant. Moreover, most patronized CAE software packages still rely on manual data input in an age when designs are robustly imbedded with metadata. This is not only counter-productive; it increases the risks for errors. Some of the areas where wide knowledge gaps exist include quantifying works in remote sites at a distance, managing construction activities by using robotics and full automation of estimate data in virtual prototypes.

Another problem in the choice of CAE software packages is the fact that existing models for selecting appropriate software packages are not based on objective frameworks as recommended in ISO/IEC 25051:2006 and 20282-1: 2006. Some of the peculiar challenges in this direction are interoperability, portability and flexibility. At the moment, it is difficult to customize how estimating applications are used, exchange file formats (e.g. quantification to planning and planning to pricing) and enable remote access. 


\section{REFERENCES}

[1] Hamlyn-Harris, H., A review and appraisal of commercially available computer-aided estimating systems for builders and civil engineers, in Department of Civil Engineering. 1979, Loughborough University of Technology: Loughborough, UK.

[2] McCaffer, R. and W. Sher, Computer-aided estimating - an interactive approach. Building Technology and Management, (United Kingdom), 1981. 19(2): p. pp 16 - 20.

[3] Oteifa, S. and A. Baldwin, Estimators' tasks and computeraided estimating systems: A survey of FCEC member companies. Construction Management and Economics, 1991. 9(6): p. 543552.

[4] Best, R., et al. Information Technology and evolution of Quantity Surveying profession - future direction. in International Construction Information Technology Conference INCIT 96 Proceedings: Bridging the Gap. 1996. Sydney, N.S.W: National conference publication (Institution of Engineers, Australia).

[5] Lowe, D. and M. Skitmore, Experiential learning in cost estimating. Construction Management and Economics, 1994. 12(5): p. 423-431.

[6] Lowe, D. and M. Skitmore, Organisational learning style and practitioner competence. Journal of Financial Management of Property and Construction, 2007. 11(3).

[7] Ogunlana, S.O., Accuracy in Design Cost Estimating. 1989, University of Technology: Loughborough, UK.

[8] Langdon, D. How we got to here 2002 Accesed on 10th October, 2008]; Available from: http://www.architecturalcadd.com/classes/caddhistory.html.

[9] Thorpe, A., Information flow in house building organisations, in Department of Civil and Building Engineering. 1992, Loughborough University of Technology: Loughborough, UK. p. 292.

[10] Lee, A., et al., A roadmap for $n D$ enabled construction in RICS Research Paper Series, S. Brown, Editor. 2006, The Royal Institution of Chattered Surveyors (RICS): London.

[11] Caputo, A.C. and P.M. Pelagagge, Parametric and neural methods for cost estimation of process vessels. International Journal of Production Economics, 2008. 112(2): p. 934-954.
[12] Cheng, M.-Y., H.-C. Tsai, and W.-S. Hsieh, Web-based conceptual cost estimates for construction projects using Evolutionary Fuzzy Neural Inference Model. Automation in Construction, 2009. 18(2): p. 164-172.

[13] Ntuen, C.A. and A.K. Mallik, Applying artificial intelligence to project cost estimating. Cost Engineering, 1987. 29(5): p. 9 13.

[14] Akintoye, A. and E. Fitzgerald, A survey of current cost estimating practices in the UK. Construction Management and Economics, 2000. 18: p. 161-172.

[15] Sher, W., Computer-aided Estimating - A guide to Good Practice. 1996, Harlow: Addison Wesley Longman Limited.

[16] Sher, W., et al., Heading into new virtual environments: what skills do design team members need? Journal of Information Technology in Construction, 2009. 14: p. 17-29.

[17] Sher, W., Computer-aided measurement - a new development. South African Builder, 1982. 61(8): p. pp 41 - 45.

[18] Sher, W., Computer applications in the construction industry. The South African Builder, 1982. 61(4): p. pp 70 - 72.

[19] Oyediran, O.S. and K.T. Odusami, A study of computer usage by Nigerian quantity surveyors. Journal of Information Technology in Construction 2005. 10: p. 291-303.

[20] Oyediran, O.S. and A. Akintola, A survey of the state of the art of e-tendering in Nigeia. Journal of Information Technology in Construction, 2011. 16(2): p. 557 - 576.

[21] Fogelstr, N.D., M. Svahnberg, and T. Gorschek, Investigating Impact of Business Risk on Requirements Selection Decisions, in Proceedings of the 2009 35th Euromicro Conference on Software Engineering and Advanced Applications. 2009, IEEE Computer Society.

[22] Arditi, D. and K. Suh, Estimating system selection expert. Construction Management and Economics, 1991. 9(4): p. 369381.

[23] Franch, X. and J.P. Carvallo, Using Quality Models in Software Package Selection. IEEE Software, 2003. 20(1): p. pp $34-41$.

[24] ISO/IEC, Software Engineering- Product Quality-Part 1: Quality Model. 2001, ISO Copyright Office: Geneva. 